\title{
Pathophysiology of Pediatric Obstructive Sleep Apnea
}

\author{
Eliot S. Katz ${ }^{1}$ and Carolyn M. D'Ambrosio ${ }^{2}$ \\ ${ }^{1}$ Division of Respiratory Diseases, Department of Medicine, Children's Hospital, and Harvard Medical School, Boston, Massachusetts; and ${ }^{2}$ Division \\ of Pulmonary Diseases, Department of Medicine, Tufts-New England Medical Center, and Tufts Medical School, Boston, Massachusetts
}

\begin{abstract}
Sleep-disordered breathing is a common and serious cause of metabolic, cardiovascular, and neurocognitive morbidity in children. The spectrum of obstructive sleep-disordered breathing ranges from habitual snoring to partial or complete airway obstruction, termed obstructive sleep apnea (OSA). Breathing patterns due to airway narrowing are highly variable, including obstructive cycling, increased respiratory effort, flow limitation, tachypnea, and/or gas exchange abnormalities. As a consequence, sleep homeostasis may be disturbed. Increased upper airway resistance is an essential component of OSA, including any combination of narrowing/ retropositioning of the maxilla/mandible and/or adenotonsillar hypertrophy. However, in addition to anatomic factors, the stability of the upper airway is predicated on neuromuscular activation, ventilatory control, and arousal threshold. During sleep, most children with OSA intermittently attain a stable breathing pattern, indicating successful neuromuscular activation. At sleep onset, airway muscle activity is reduced, ventilatory variability increases, and an apneic threshold slightly below eupneic levels is observed in non-REM sleep. Airway collapse is offset by pharyngeal dilator activity in response to hypercapnia and negative lumenal pressure. Ventilatory overshoot results in sudden reduction in airway muscle activation, contributing to obstruction during non-REM sleep. Arousal from sleep exacerbates ventilatory instability and, thus, obstructive cycling. Paroxysmal reductions in pharyngeal dilator activity related to central REM sleep processes likely account for the disproportionate severity of OSA observed during REM sleep. Understanding the pathophysiology of pediatric OSA may permit more precise clinical phenotyping, and therefore improve or target therapies related to anatomy, neuromuscular compensation, ventilatory control, and/or arousal threshold.
\end{abstract}

Keywords: children; sleep-disordered breathing

The essential feature of obstructive sleep apnea (OSA) in children is increased upper airway resistance during sleep. Airway narrowing may be due to craniofacial abnormalities and/or soft tissue hypertrophy. The resultant breathing patterns during sleep are highly variable, but include obstructive cycling, increased respiratory effort, flow limitation, tachypnea, and/or gas exchange abnormalities. Consequently, sleep disruption occurs, ranging from visible electrocortical arousal to subtle autonomic activation. The threshold level of obstruction leading to interference with sleep homeostasis has not been established.

The pathophysiology of OSA in children is a complex interaction between an airway predisposed toward collapse and neuromuscular compensation. Anatomic measures of the airway lumen, soft tissue, and skeleton are of critical importance to

(Received in original form July 31, 2007; accepted in final form September 14, 2007) Supported by grant NIH/NHLBI HL073238 and grant MO1 RR02172 to Children's Hospital, Boston, General Clinical Research Center by the National Center for Research Resources, National Institutes of Health (to E.S.K.).

Correspondence and requests for reprints should be addressed to Eliot S. Katz, M.D., Division of Respiratory Diseases, Mailstop 208, Children's Hospital, Boston, 300 Longwood Avenue, Boston, MA 02115. E-mail: eliot.katz@childrens. harvard.edu

Proc Am Thorac Soc Vol 5. pp 253-262, 2008

DOI: $10.1513 /$ pats.200707-111MG

Internet address: www.atsjournals.org the development of OSA, although they do not completely account for the pattern of sleep-disordered breathing. This indicates a role for other determinants of airway patency such as neuromuscular activation, ventilatory control, and arousal threshold. At sleep onset, airway muscle activity is reduced, ventilatory variability increases, and an apneic threshold slightly below eupneic levels is observed in non-REM sleep. Airway collapse is offset by pharyngeal dilator activity in response to hypercapnia and negative lumenal pressure. Ventilatory overshoot results in sudden reduction in airway muscle activation, contributing to obstruction during non-REM sleep. Most children with severe OSA will be able to sustain stable breathing during a large portion of sleep, consistent with successful neuromuscular compensation. Respiratory control mechanisms modulate ventilation and pharyngeal dilator activation. Arousal from sleep contributes to ventilatory instability and, thus, obstructive cycling. Paroxysmal reductions in pharyngeal dilator activity related to central REM sleep processes likely account for the disproportionate severity of OSA observed during REM sleep.

This review focuses on the pathophysiology of OSA in otherwise normal children. Comprehensive reviews comparing OSA in children with infants (1) and adults (2) have been published elsewhere.

\section{CLINICAL OBSERVATIONS}

To appreciate the factors that contribute to airway collapse, it is helpful to contrast the breathing patterns during sleep in children with and without OSA. Normative data from several, large samples of nonsnoring, normal children indicate that (1) obstructive apneas and hypopneas rarely occur; (2) inspiratory flow limitation and respiratory effort-related arousals are uncommon; (3) oxygen saturation rarely drops below $90 \%$, even during normal 10 - to 15 -second respiratory pauses following sighs or movements; and (4) during non-REM sleep, respiratory rate decreases and end-tidal $\mathrm{CO}_{2}$ increases 3-4 mm Hg (3-7). Thus, despite ethnic differences in these studies the findings were remarkably similar, indicating the rarity of sleep-disordered breathing in normal children.

Various sleep-disordered breathing patterns have been described in children, suggesting that distinct clinical phenotypes may exist. The spectrum of obstructive breathing ranges from persistent nonapneic/hypopneic, habitual snoring to frank, intermittent occlusion seen in OSA. Habitual snoring has been reported in $3-12 \%$ of the general pediatric population, although only $1-3 \%$ will have OSA (8-10). Children with habitual snoring lack apnea, hypopnea, respiratory effort-related arousals, and gas exchange abnormalities. This suggests that neuromuscular compensation was successful at attaining stable breathing during sleep, and that any increased respiratory effort remained below the threshold level for arousal. Nevertheless, children with habitual snoring may still have recognizable breathing abnormalities during sleep including inspiratory flow limitation, increased respiratory effort and tachypnea $(11,12)$, and evidence of subtle alterations in sleep homeostasis (11). A related polysomnographic pattern, termed obstructive hypoventilation, features 
snoring, stable increased respiratory effort, and hypercapnia, but not frank apnea, hypopnea, or respiratory arousal (13).

The upper airway resistance syndrome is characterized by brief, repetitive respiratory effort-related arousals during sleep in the absence of overt apnea, hypopnea, or gas exchange abnormalities (14) Children with upper airway resistance syndrome arouse with less respiratory effort than do children with OSA or habitual snoring, suggesting a possible etiologic role for diminished arousal threshold (15). Finally, children with OSA manifest recurrent episodes of partial or complete airway obstruction. During non-REM sleep, obstructive events are generally accompanied by an initial decrease in respiratory effort, followed by a graded increase. In REM sleep, the respiratory effort is more variable and may increase or decrease during an obstruction. Increased upper airway resistance is correlated with the severity of OSA in children (16). In addition to adenotonsillar hypertrophy, causes of airway narrowing include allergic rhinitis, turbinate hypertrophy, deviated septum, and maxillary constriction (17).

Most children with severe OSA are able to maintain normal sleep state distribution, particularly REM and slow wave sleep, despite intermittent obstruction $(18,19)$. However, subtle abnormalities of sleep microstructure have been reported (18, 20, 21). Obstructive events occur disproportionately in REM sleep and are rare during slow wave sleep (19). Dayyat and coworkers demonstrated that obese children with OSA had more obstructive events in the supine position, whereas obstructive events in nonobese children with OSA were more severe in the prone or side positions (22). This suggests that there are important physiological differences between obese and nonobese airways. Lateral positioning has been shown to increase the size of the airway by both magnetic resonance imaging (MRI) (23) and endoscopy (24). The degree of neck flexion was not quantified in these studies, and may also affect airway collapsibility, but these data are not available in children.

Insight into the pathophysiology of pediatric OSA can also be derived from treatment studies. The importance of increased upper airway resistance is evident by the improvement in OSA in selected populations after turbinectomy (17), septal repair (17), administration of intranasal corticosteroids (25), and rapid maxillary expansion (26). Also, children with persistent OSA after an adenotonsillectomy are more likely to have enlarged turbinates, a deviated septum, and/or retroposition of the mandible (27). Two large studies have documented persistent OSA in otherwise normal children with adenotonsillar hypertrophy after adenotonsillectomy. Tauman and colleagues reported complete normalization of patients with OSA after adenotonsillectomy (apnea-hypopnea index $[\mathrm{AHI}]<1$ ) in only $25 \%$ of patients, with $46 \%$ having persistent mild OSA $(1<$ AHI $<$ 5 ), and $29 \%$ having at least moderate OSA (AHI > 5) (28). Similarly, Guilleminault and coworkers reported that $45 \%$ of children with OSA had persistent OSA after adenotonsillectomy (27). Together, these studies indicate that adenotonsillar hypertrophy is only one of several important determinants of OSA in children.

\section{ANATOMY}

Children with OSA have narrower pharyngeal airways compared with control children during wakefulness (29), sedation (30), and paralysis (31). This has been demonstrated by cephalometry (32), acoustic reflection (29), endoscopy (31), and MRI (30, 33, 34). However, anatomic comparison between children with OSA and children with habitual snoring has not yet been performed.

\section{Skeletal}

Children with craniofacial dysmorphology involving hypoplasia or retropositioning of the mandible or maxilla frequently have OSA. The contribution of skeletal abnormalities to the development of OSA in otherwise normal children is controversial. Arens and coworkers reported that no measures of maxillary and mandibular width, length, or volume differed between patients with OSA and normal control subjects (30). However, cephalometric studies in children with OSA, which evaluate both size and relative position of the facial skeleton, frequently report narrower maxilla $(35)$, mandibular retrognathia $(32,36)$, longer lower facial height $(32,36,37)$, and caudal placement of the hyoid bone (38). A referral bias may explain some of the differences in data between the sleep and dental clinics in the various studies cited above. It is reasonable to conclude that craniofacial skeletal abnormalities may contribute to the development of OSA in some otherwise normal children. Age and sex may also be an important determinant of OSA in children, based on a report that prepubertal males and females have similar airway lengths, but postpubertal males have longer airways than do females (39). In adults, airway length has been associated with increased airway collapsibility and there is a male predominance of OSA (40).

\section{Pharyngeal Soft Tissues and Lumen}

Children with OSA have larger adenoids, tonsils, and soft palates compared with normal control subjects (30) (Figure 1). Consequently, the pharyngeal airway is smaller in OSA as measured under sedation by MRI (30) and using paralysis with endoscopy (31). In sedated, young children ( $4.8 \pm 2.1 \mathrm{yr}$; range, 1.9-9.3 yr), there was a positive linear correlation between the tonsil and adenoid volume and the AHI $\left(r^{2}=0.26\right)$, but there was no such correlation with airway volume (30). In unsedated, older children $(9.5 \pm 1.2 \mathrm{yr}$; range, $7-12 \mathrm{yr})$, the tonsil crosssectional area (CSA) $\left(r^{2}=0.44\right)$, soft palate CSA $\left(r^{2}=0.39\right)$, oropharyngeal volume $\left(r^{2}=0.27\right)$, and ratio of the retropalatal airway to soft palate CSA $\left(r^{2}=0.49\right)$ strongly correlated (tonsils and palate) or inversely correlated (ratio of retropalatal airway to soft palate) with the obstructive AHI (33). The parapharyngeal fat pad did not significantly contribute to apnea severity in either the young (30) or older (33) children. Remarkably, in older children, a multiple linear regression analysis indicated that $74.3 \%$ of the variance in obstructive AHI could be explained by the tonsil and soft palate CSAs (33). A correlation with apnea severity was observed with the younger children's combined adenotonsillar volume (30), but not with the older children's combined adenotonsillar CSA (33). Cephalometric data similarly indicate that younger children have larger soft tissues relative to the facial skeleton than do older children (41). Thus, the contributions of soft tissue structures to the pathophysiology of OSA may vary with the age of children (see below, Craniofacial Development).

Dynamic inspiratory airway narrowing during tidal breathing was much greater in children with OSA compared with normal control subjects (mean age, $4.3 \pm 2.3 \mathrm{yr}$; age range, 2-7.2 yr [42]; mean age, $9.7 \mathrm{yr}$; age range, 0.5-19 yr [34]) (see Figure 1). This indicates that patients with OSA have either greater lumenal pressure oscillations due to increased upper airway resistance and/or an increase in airway compliance. Nasal resistance measured by anterior rhinometry is reported to be increased in children with OSA compared with control subjects (16). Even in asymptomatic children, adenotonsillar size correlates with increased inspiratory airway narrowing at the nasopharynx (43).

During tidal breathing, the narrowest airway segment occurs at the site of overlap between the tonsil and adenoid in both 

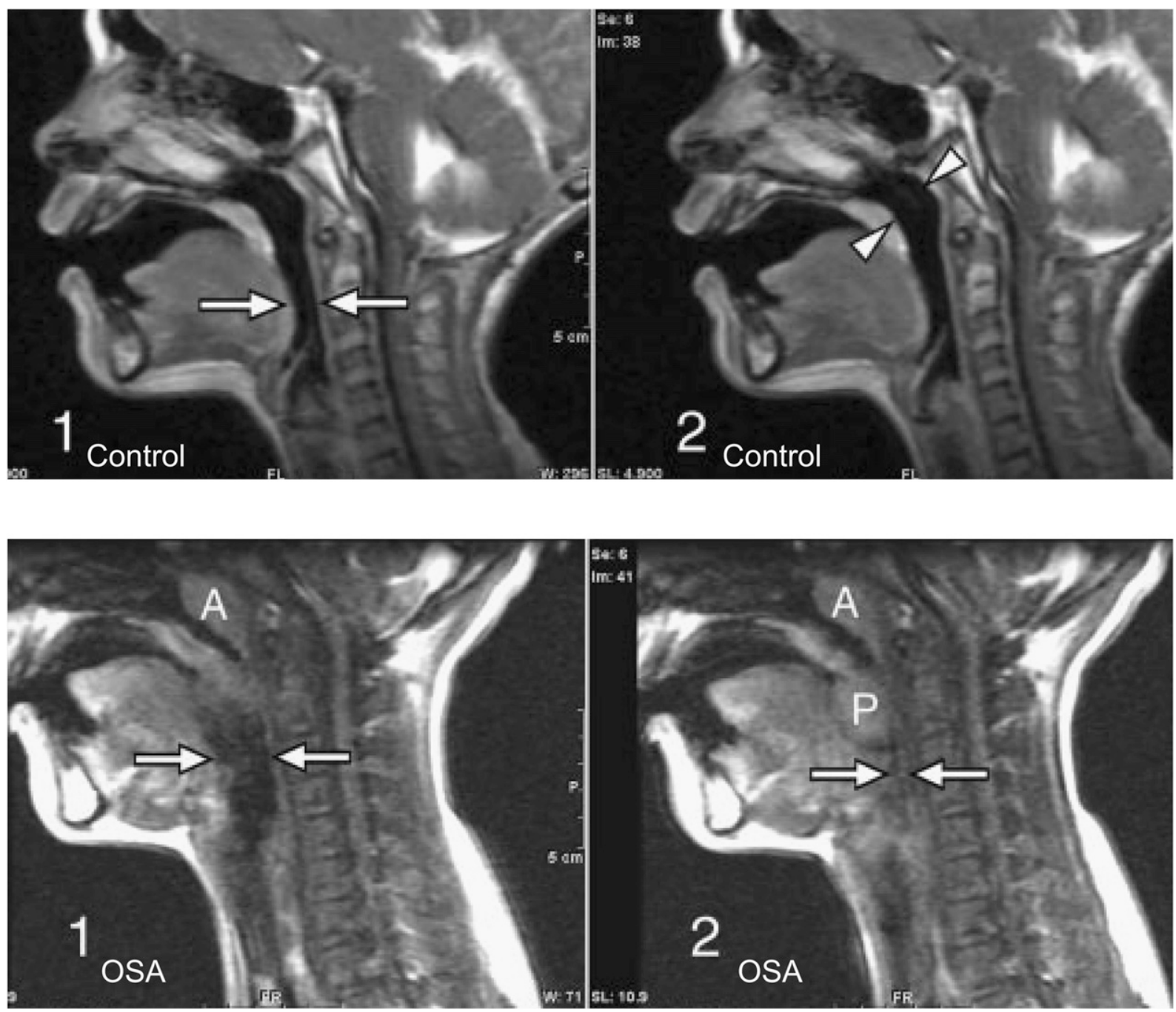

Figure 1. Top: Three-year-old normal control male subject. Sagittal images from various points in the respiratory cycle show no significant change in airway diameter at the level of the hypopharynx (arrows in image 1) or nasopharynx (arrowheads in image 2). Bottom: Eleven-year-old male patient with obstructive sleep apnea (OSA). Sagittal images from various points of the respiratory cycle demonstrate airway collapse at the level of the hypopharynx (arrows in images 1 and 2 ). The palatine tonsils ( $P$ in image 2 ) are enlarged and are seen to move inferiorly and medially during the respiratory cycle to obstruct the airway (image 2 ). The adenoids are enlarged ( $A$ in images 1 and 2 ). Modified by permission from Reference 34.

younger and older children $(33,44)$. The site of airway narrowing during obstructive events in children with OSA has been measured during sedation, paralysis, and sleep by multiple techniques, including endoscopy and imaging studies. Direct visualization of the airway during paralysis in normal children requires negative pressure to collapse the airway (31). This technique demonstrates obstruction at the level of the soft palate $(54 \%)$, tonsil $(15 \%)$, or the tongue (31\%) (31). By contrast, children with OSA under paralysis obstructed predominantly at the level of the adenoids (57\%), soft palate $(29 \%)$, and tonsil (14\%) (31). Importantly, children with OSA also had increased collapsibility at the level of the soft palate and retroglossal area, indicating a generalized increased collapsibility of the pharynx compared with normal control subjects (31). Using cine MRI during sedation, Donnelly and coworkers reported that (1) intermittent or fixed hypopharyngeal airway collapse was observed in $81 \%$ of children with OSA, but in none of the normal control subjects; and (2) patients with OSA were more likely to have intermittent airway collapse at the level of the nasopharynx (34). Thus, airway narrowing likely necessitates increasingly negative airway pressures to sustain minute ventilation, which results in airway collapse at multiple sites.

\section{Craniofacial Development}

At birth, the face is about $40 \%$ of adult size, increasing to $65 \%$ at 3 years of age, and is only completed after puberty. Facial growth is influenced principally by genetic factors, but environmental inputs may also contribute, including route of breathing. Considerable evidence supports the view that upper airway obstruction and mouth breathing induce morphologic skeletal changes in the maxilla and mandible. Importantly, adverse craniofacial development may be at least partially reversible after treatment $(37,45,46)$.

A cross-sectional MRI study, in a convenience sample of children that excluded serious illnesses, reported that the soft tissues and facial skeleton grew linearly and in proportion to each other between 1 and 11 years of age (47). By contrast, a longitudinal cephalometric study in normal children reported that the airway soft tissues grow more rapidly than the skeleton 
between 3 and 5 years of age, resulting in pharyngeal airway narrowing during this interval (41). This is consistent with the reported peak prevalence of OSA in children.

Mouth-breathing children habitually lower their mandible, which may influence dentoalveolar morphology, resulting in a high-arched palate, narrow maxilla, retrognathia, and increased lower facial height. This constellation of findings has been termed the "long face syndrome," and is similar to the reported cephalometric findings in children with OSA $(32,36,37)$. Thus, not only does upper airway obstruction predispose to OSA, but it also has an adverse effect on craniofacial development, posing an increased future risk of OSA.

Long-term follow-up studies of children with OSA after adenotonsillar removal indicate an increased incidence of snoring, increased respiratory effort, and OSA $(48,49)$, suggesting residual craniofacial narrowing. However, normalization of some cephalometric measures after treatment of upper airway obstruction in children with OSA has been reported $(37,45,46)$. Resolution of both open bites and cross-bites was observed 2 years after tonsillectomy in most patients (46). A resolution of mandible and maxillary inclination abnormalities, and lower face height, was observed 5 years after an adenotonsillectomy in children with OSA (37). Thus, relief of upper airway obstruction during periods of rapid facial growth may normalize dentofacial abnormalities that predispose to OSA. If treatment is initiated in younger children (before $6 \mathrm{yr}$ of age), the long-term dentoalveolar development is more likely to normalize (46).

\section{Obesity}

The prevalence of childhood obesity has tripled since the early 1980 s, and is presently estimated to be $16 \%$. The risk of OSA in obese children is high at $36 \%$ (50), and may exceed $60 \%$ if habitual snoring is present (51). Most obese children with OSA will also have adenotonsillar hypertrophy (51). Surgical removal of enlarged tonsils and adenoids in obese children with OSA results in a marked improvement of the AHI, but $76 \%$ have residual OSA (52). There is no consistent relationship between pediatric OSA and measures of fat distribution (53). Although imaging studies specific to obese children have not been performed, adult studies indicate that increased deposition of fat in the parapharyngeal fat pads near and within the soft palate contributes to airway obstruction. Obese individuals also have lower lung volumes, increasing both airway collapsibility and gas exchange abnormalities.

\section{PATHOLOGY}

Chronic vibratory stress on the airway soft tissues could adversely affect pharyngeal dilator function by inducing pathological changes to nerves, muscles, or sensory innervation. De Vuono and coworkers performed blinded, histologic analysis on palatopharyngeal biopsies in mouth-breathing children with adenotonsillar hypertrophy undergoing tonsillectomy (54). Patients were categorized into three groups, OSA, habitual snoring, and normal, based on nocturnal polysomnography. Histopathological findings were similar between the groups, indicating that it is unlikely that a primary or secondary neuromyopathy is an important determinant of OSA (54).

The negative pressure reflex is an important mediator of upper airway neuromuscular compensation. It is plausible that mucosal inflammation or edema could impair the afferent limb of this reflex. It is hypothesized that snoring induces a mucosal inflammatory response resulting in swelling, affecting upper airway resistance and/or collapsibility. Blunted respiratory perception in children with OSA has been reported by measuring respiratory-related evoked potentials (55). Direct evidence of inflammatory changes to the upper airway includes the increased expression of leukotriene receptors in tonsillar tissue from children with OSA compared with children with recurrent throat infections (56). Also, treatment studies using intranasal corticosteroids (25), leukotriene receptor antagonists (57), or both (58), result in a reduction in OSA severity.

\section{VISCOELASTIC MECHANICS}

The upper airway is a compliant tube, the cross-sectional area and shape of which are nonlinearly dependent on the transmural pressure, termed the "tube" law (Figure 2). As the lumenal pressure becomes more negative, the airway size decreases until a "buckling" point is reached, at which the airway markedly collapses. Thus, there is a narrow, highly compliant range over which small changes in pressure produce large changes in airway cross-sectional area. This has important implications in the pathophysiology of OSA, resulting in rapid airway closure. Conversely, the rapid opening of the airway after an apnea/hypopnea may yield a ventilatory overshoot producing respiratory instability and, thus, obstructive cycling.

The viscoelastic properties of the airway in children have been evaluated during anesthesia under complete paralysis (31). The mean airway closing pressure is greater for children with OSA compared with control subjects, $+3.5 \pm 4.3$ and $-7.4 \pm$ $4.9 \mathrm{~cm} \mathrm{H}_{2} \mathrm{O}$, respectively (31) (see Figure 2). Children with OSA have higher airway compliance than do control subjects near the closing pressure, contributing to greater airway instability. Post mortem analysis demonstrated that the passive airway closing pressure was $-0.7 \pm 2 \mathrm{~cm} \mathrm{H}_{2} \mathrm{O}$, indicating that neuromuscular compensation must be active in the living infant (59). However, the airway opening pressure was much higher, $+5 \pm 2.4 \mathrm{~cm}$ $\mathrm{H}_{2} \mathrm{O}$, likely indicating hysteresis due to surface forces (59). Extension of the neck decreased the closing pressure, thereby stabilizing the airway (59). Neck extension is a compensatory strategy often observed in children with OSA to mitigate the severity of OSA.

\section{FLOW MECHANICS}

\section{Starling Resistor Model}

Airflow through the upper airway has the mechanical properties of a Starling resistor (60-63). The essential features of this model are a collapsible segment dividing upstream (nasal) and downstream (tracheal) segments with fixed resistances. The lumenal pressure at which airway collapse occurs is termed the critical closing pressure (Pcrit). In humans, the Pcrit is an index of both the viscoelastic and neuromuscular properties of the pharynx. When downstream pressure is above the Pcrit,

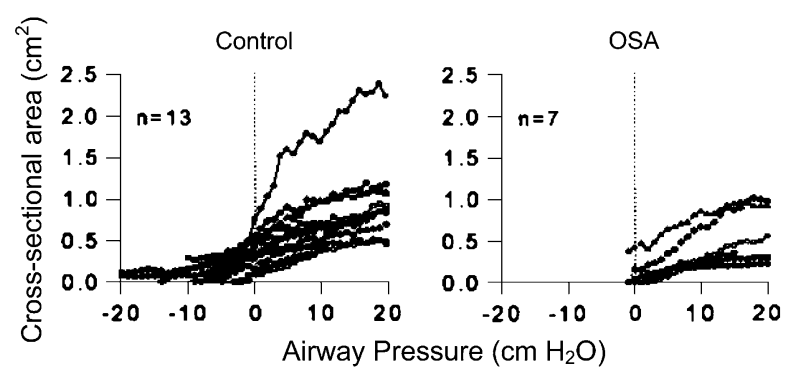

Figure 2. Static airway cross-sectional area versus pressure curves at the level of the soft palate for a series of children with obstructive sleep apnea (OSA) (right) and control subjects (left). The closing pressure defined as zero area is higher in OSA. Modified by permission from Reference 31. 
airflow is proportional to the pressure gradient across the airway. However, when downstream pressure falls below the Pcrit, flow limitation is observed. Thus, maximal airflow will vary in relation to the upstream pressure and Pcrit, but not the downstream variables. Techniques to measure the Pcrit differ considerably in the degree of airway neuromuscular activation. Thus, the relative importance of the viscoelastic and neuromuscular components of pharyngeal collapsibility may be estimated (Figure 3).

Pcrit can be measured by brief negative pressure challenges via nasal mask $(60,62)$. Pcrit is extrapolated as the zero flow point ( $x$ intercept) of the mask pressure versus maximal inspiratory flow curve (see Figure 3 ). The negative pressure challenges have been of two types, termed relatively passive and active, which differ in degree of neuromuscular activation allowed. The relatively passive technique consists of intermittent pressure drops of three to five breaths, followed by a return to a pressure sufficient to achieve non-flow-limited breathing. The relatively passive technique attempts to minimize the effect of neuromuscular activation. By contrast, the active technique uses a progressive drop in airway pressure, allowing muscle activation (62). Comparing the changes in collapsibility between techniques (relatively passive vs. active) provides a measure of neuromuscular activation. Empirically, many children will not demonstrate a decrease in maximal flow even at very negative mask pressures, suggesting low airway compliance. In this case, it is desirable simply to evaluate the slope of the mask pressure-maximal flow curve as a measure of airway collapsibility, combining both structural and neuromuscular components.

\section{Airflow Data}

Children with OSA have a higher Pcrit than do control subjects (62) and children with habitual snoring (60). Pcrit correlates with the severity of OSA, and decreases after adenotonsillectomy (60). Interestingly, the Pcrit in patients with OSA after

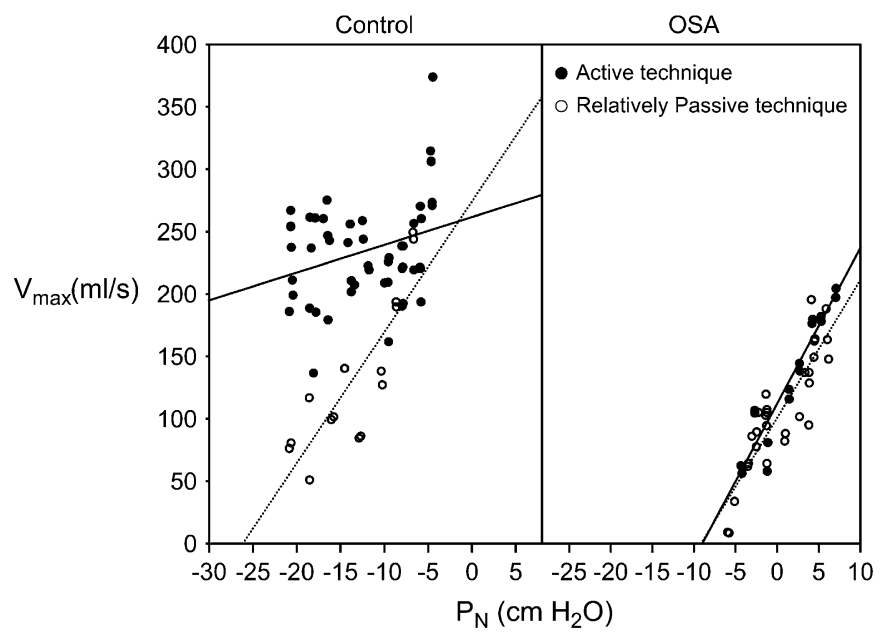

Figure 3. Left: Normal control child. Nasal pressure $\left(\mathrm{P}_{\mathrm{N}}\right)$ versus maximal inspiratory flow $\left(\dot{V}_{I_{\text {max }}}\right)$ is plotted subsequent to a series of negative pressure challenges, using the active (solid circles) and relatively passive (open circles) techniques. The relatively passive technique minimizes neuromuscular activation of the upper airway and results in a critical closing pressure of $-22 \mathrm{~cm} \mathrm{H}_{2} \mathrm{O}$. The active technique facilitates pharyngeal dilator activity and resulted in a less collapsible upper airway. Right: Patient with obstructive sleep apnea (OSA). There is no change in airway collapsibility between the active and relatively passive techniques. Modified by permission from Reference 62 . adenotonsillectomy did not decrease to the level in control subjects (62), or even primary snorers (60), suggesting that subtle abnormalities of anatomy or neuromuscular control remain after treatment (mean age of subjects in both studies: $8 \mathrm{yr}$ old; age range, 5-11 yr). In normal children, the relatively passive Pcrit was $-25 \mathrm{~cm} \mathrm{H}_{2} \mathrm{O}$ and the active Pcrit was essentially unmeasurable because the airway is not collapsible (62). Between 10 and 16 years of age there is a small, but significant, increase in airway collapsibility in older children, independent of Tanner stage (64). Under general anesthesia with muscle paralysis, the mean airway closing pressure (Pclose) in normal children is $-7.4 \mathrm{~cm} \mathrm{H}_{2} \mathrm{O}$ (31). A comparison of the Pcrit (relatively passive, $-25 \mathrm{~cm} \mathrm{H}_{2} \mathrm{O}$, sleep) and Pclose $\left(-7.4 \mathrm{~cm} \mathrm{H}_{2} \mathrm{O}\right.$, paralysis) in normal children indicates considerable activity of the upper airway musculature during sleep. By contrast, in children with OSA, the relatively passive Pcrit was $-5 \mathrm{~cm} \mathrm{H}_{2} \mathrm{O}$, the active Pcrit was $-7 \mathrm{~cm} \mathrm{H}_{2} \mathrm{O}$, and the Pclose was $-2 \mathrm{~cm}$ $\mathrm{H}_{2} \mathrm{O}$, indicating less effective neuromuscular compensation $(31,62)$.

Hypercapnia increases maximal inspiratory airflow (reduces Pcrit and slope of the mask pressure-maximal flow curve) in normal children (65), presumably also by augmenting airway neuromotor activity. By contrast, hypercapnia generally does not decrease airway compliance in children with OSA (62). Thus, children with OSA have more collapsible airways during sleep at baseline, as well as impaired airflow responses to negative pressure and hypercapnia, compared with normal children. The hypercapnic ventilatory response during wakefulness and sleep is similar in children with and without OSA $(66,67)$. Whether the impaired responses to negative pressure in children with OSA are related to neural processing or to a phenomenon secondary to impaired afferent receptors due to mucosal swelling/inflammation remains to be determined.

\section{NEUROMUSCULAR COMPENSATION OF THE UPPER AIRWAY}

The upper airway lumenal dimension is determined by the balance between the viscoelastic properties of the pharynx, neuromuscular activity, and the transmural pressure. Upper airway muscles that are phasically activated during inspiration increase both the lumenal size and stiffness of the airway. The significance of muscular modulation of airway patency in children is suggested by the following clinical observations: (1) apnea is observed predominantly in REM and stage 2 sleep rather than in wakefulness or slow wave sleep; (2) although sedated and anesthetized children with OSA have narrower and more collapsible airways compared with normal control children, there is considerable overlap $(30,31)$; and (3) during sleep, most children with OSA intermittently attain a stable breathing pattern, suggesting that reflex neuromuscular activation below the arousal threshold is possible. Thus, the anatomic and viscoelastic properties of the airway are not the sole determinants of airway patency.

Pharyngeal dilator muscle activity, including the genioglossus, hyoglossus, and styloglossus, modulates flow through the upper airway. Although it is believed that these muscles act in unison, the genioglossus is the most easily measured. The genioglossus produces forward movement of the tongue, increasing oropharyngeal airway size and stiffness. Both tonic and phasic inspiratory genioglossal activity have been noted in children (68).

\section{Sleep State Effect}

During wakefulness, children with OSA have an increased genioglossus EMG (EMGgg) compared with control children 
(68). This is thought to represent reflex activation by mucosal mechanoreceptors sensing negative airway pressure. Further, applying topical anesthesia during wakefulness to the airway of children with and without OSA results in a greater decline in airway size in patients with OSA (69). Thus, mucosal mechanoreceptor-induced pharyngeal dilator activity is more active in patients with OSA (69) during wakefulness.

During the sleep onset period, the EMGgg decreases in both patients with OSA and control subjects, but more so in the former (68). This suggests that central respiratory drive and/or neuromuscular compensatory mechanisms are diminished during the transition to sleep. The reduction in muscle activity is associated with increased airway resistance and collapsibility. As stable non-REM sleep is established over several minutes there is a divergence in the EMGgg activity between patients with OSA and control subjects. In normal children, the EMGgg remains below the wakeful baseline during stable stage 2 and stage 4 sleep, suggesting that additional neuromuscular activity is not necessary with a mechanically stable airway (70). However, most children with severe OSA have a rebound increase in EMGgg activity during stage 2 sleep, consistent with a reflex driven by mechano- and/or chemoreceptors (70). There is a significant correlation between OSA severity (i.e., AHI) and EMGgg activity in all sleep stages. Finally, applying continuous positive airway pressure to patients with OSA during sleep results in a reduction in the EMGgg coincident with reductions in respiratory effort and hypercapnia (70).

Obstructive events occur most frequently in children during REM sleep, followed by stage 2, and are rare in slow wave sleep (19). REM sleep is a heterogeneous state with paroxysmal phasic processes that both increase and decrease EMGgg activity (70). Overall in REM sleep, there is a reduction in tonic and phasic EMGgg activity. However, there is a marked increase in the variability of EMGgg during REM sleep in children with and without OSA (70). Sudden reductions in EMGgg activity during REM sleep lasting a few seconds are observed coincident with apneic and hypopneic events (70). The vulnerability of REM sleep to sleep-disordered breathing may also be related to generalized muscle atonia and relatively lower lung volume (71). Low lung volumes may influence the upper airway by decreasing "tracheal tug," and therefore increasing airway collapsibility $(72,73)$. In addition, low lung volumes decrease the oxygen reserve and adversely affect ventilation-perfusion matching, resulting in more rapid gas exchange abnormalities.

\section{Negative Pressure Reflex}

Collapse of the upper airway reduces minute ventilation and induces a compensatory increase in respiratory effort. This results in large negative lumenal pressure changes during inspiration. The negative pressure reflex consists of airway mucosal mechanoreceptor-induced activation of pharyngeal dilator muscles. This mechanism decreases airway collapsibility, resulting in increased minute ventilation. Children who successfully augment airflow early during airway collapse may be spared the progression to apneas or hypopneas that would be more likely to result in sleep disruption.

The negative pressure reflex has been studied in children using inspiratory resistance loading (74) and by applying negative pressure through a nose mask (61). These studies have demonstrated a variety of strategies to compensate for increased upper airway resistance. Using inspiratory resistance loading, Marcus and coworkers reported that patients with OSA developed intermittent obstructive cycling associated with arousals (74). Thus, children with OSA must rely on arousal mechanisms to sustain minute ventilation, which disrupt sleep homeostasis. By contrast, normal children respond to loading with an increased inspiratory time, and were able to sustain loads without arousing for several minutes (74). Reflex mechanisms that alter respiratory timing and increase pharyngeal dilator activity without arousal are less disruptive to sleep homeostasis.

The negative pressure reflex can be observed more directly by experimentally lowering mask pressure. In normal children, negative pressure challenges in the range of $-10 \mathrm{~cm} \mathrm{H}_{2} \mathrm{O}$ generally resulted in a return of the minute ventilation to baseline by breath number 5 (61). Importantly, breaths without a visible EEG arousal tended to approach baseline minute ventilation without a significant overshoot, thus contributing to ventilatory stability. There is wide intersubject variability in inspiratory EMGgg activation in response to negative pressure, which may represent an intermediate phenotype affecting the expression of sleep apnea (Figure 4). The increased EMGgg induced by negative pressure challenge is associated with increased flow, increased respiratory rate, and decreased airway collapsibility (61).

\section{AROUSAL}

Arousal from sleep immediately opens the airway and normalizes gas exchange abnormalities. However, arousal may also be considered an adverse epiphenomenon that potentiates obstructive cycling and interferes with sleep homeostasis (75). Arousal is a graded phenomenon resulting in reflex activation of pharyngeal dilator muscles and central nervous system activation, ranging from visible EEG arousal to subtle autonomic changes. The principal stimulus for arousal appears to be respiratory effort and hypercapnia, whereas hypoxemia is a poor arousing stimulus. Increased respiratory effort alone may induce subtle frequency changes in the surface EEG $(11,20)$. This is consistent with clinical studies demonstrating that snoring with increased respiratory effort, but without discrete obstructive events, is associated with adverse neurodevelopmental outcomes (76).

The arousal threshold to negative pressure challenges is highest in stage 4, intermediate in stage 2, and lowest in REM sleep (61). A high arousal threshold may stabilize breathing by allowing time for mechano- and/or chemoreceptor recruitment of pharyngeal dilator muscles. Marcus and coworkers have reported that children with OSA have normal ventilatory responses to hypoxemia and hypercapnia during wakefulness (67) and stage 2 sleep (66). However, children with OSA have decreased arousal responsiveness (that is, require a greater stimulus) during sleep to respiratory loading and hypercapnia, compared with normal control subjects $(66,74)$. The etiology of the increased arousal threshold to respiratory stimuli has not been established, and may be a secondary phenomenon. However, the arousal threshold to acoustic stimuli does not differ between the two groups, suggesting that children with OSA do not have a global arousal deficit (77).

Children with severe OSA have a visible EEG arousal with only $50 \%$ of obstructive events $(15,78)$ and often have a normal sleep state distribution (19). However, evidence of autonomic activation was observed subsequent to obstructive apneas, hypopneas, and respiratory effort-related arousals 91, 83, and $80 \%$ of the time, respectively (15). In addition, several studies indicate that subtle abnormalities of sleep architecture occur in children with OSA, including decreased spontaneous arousals (18), increased slow wave sleep (18), respiratory cycle-related EEG changes (20), and alteration in the amount of the cyclic alternating pattern (21). 
A

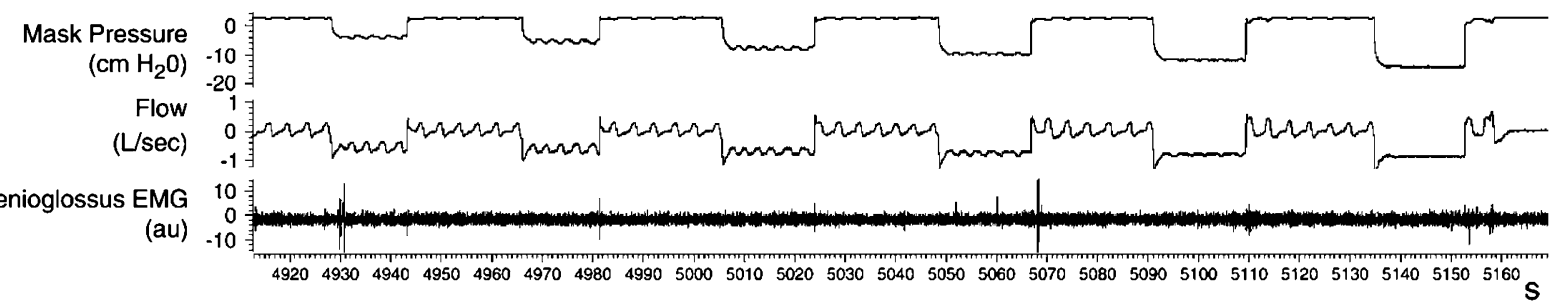

B

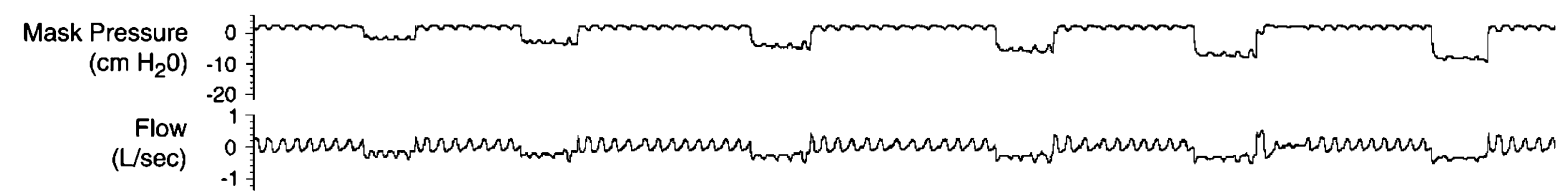

Raw Genioglossus EMG

(au)
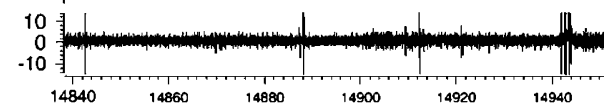

14960

14980

15000

$15020 \quad 15040$

15060 1508015100

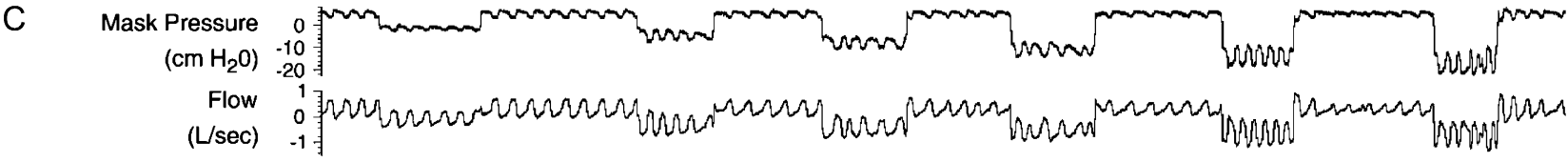

Raw Genioglossus EMG

(au)
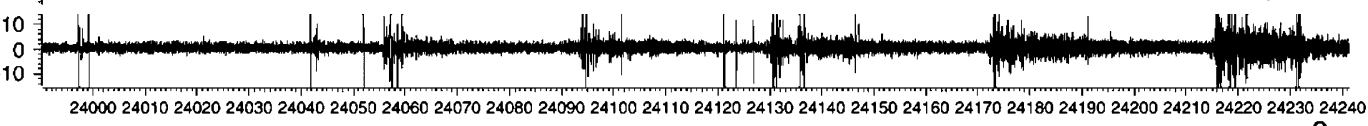

Figure 4. Raw data from three normal children during stage 4 sleep, demonstrating the range of genioglossus EMG (EMGgg) responsiveness and nasal airflow (Flow) during six negative pressure challenges. Each tracing represents approximately 4 minutes. $(A)$ No increase in the EMGgg or flow is evident during the negative pressure challenges. (B) A small increase in the EMGgg occurs during challenges 2-6. An increase in inspiratory flow is evident on breaths 4 and 5 during challenges 2-4. (C) A brisk EMGgg response accompanies challenges $2-6$ and is associated with flow at or above baseline without arousal. Reproduced by permission from Reference 61.

\section{VENTILATORY CONTROL}

Oxygen and carbon dioxide tensions are regulated within narrow limits during wakefulness in children with and without OSA. However, during sleep, regular oscillations in ventilation are observed during non-REM sleep, and irregular variations occur in REM sleep. The principal determinant of central respiratory drive is the carbon dioxide level. During nonREM sleep, the ventilatory response to $\mathrm{CO}_{2}$ is robust, and hyperpnea may lead to a ventilatory overshoot. Consequently,
$\mathrm{CO}_{2}$ levels may drop below an apneic threshold that is a unique property of non-REM sleep. As a result, there is a decrease in the central respiratory drive and innervation of the pharyngeal musculature producing narrowing of the airway, and thus initiating an obstructive event in a predisposed airway. A greater reduction in $\mathrm{CO}_{2}$ levels may result in complete loss of phasic central respiratory output, resulting in a central apnea. This apnea threshold during non-REM sleep may be close (1 $\mathrm{mm} \mathrm{Hg}$ ) to eupneic $\mathrm{CO}_{2}$ levels, producing a potentially unstable situation (79). Central, mixed, and obstructive apneas in infants
C3-A2

Thermistor

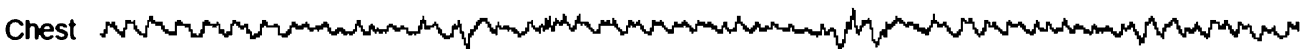

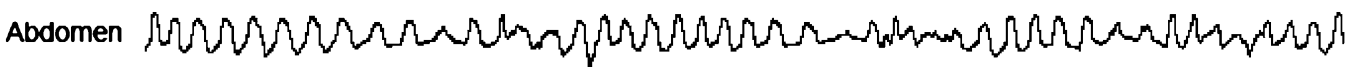
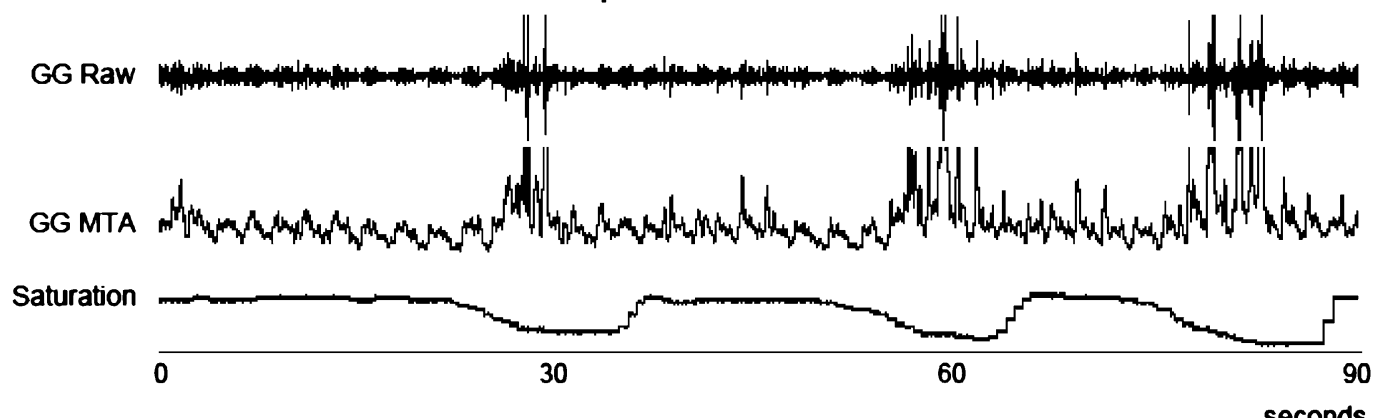

Figure 5. A series of apneichypopneic events associated with reductions in the tonic and phasic genioglossal electromyogram (EMGgg). GG = genioglossus; MTA = moving time average. Reproduced by permission from Reference 70 . 
and children all occur at the nadir of oscillations in ventilation (80) and genioglossal activity (70). Breathing exogenous carbon dioxide has been shown to decrease obstructive apneas and flow limitation in children with OSA, presumably by augmenting pharyngeal dilator activity (66), and to decrease central apneas in infants (81).

Arousal from sleep increases the gain of the central chemoreceptors and augments neuromuscular activation of the upper airway, thereby decreasing airway resistance. Ventilatory cycling in patients with OSA is facilitated by large changes in tidal volume occurring as the airway opens and closes. If the obstructive event is associated with an arousal, the ventilatory overshoot is magnified (61). The airways most vulnerable are those with a Pcrit near atmospheric pressure (82). Thus, arousal has a destabilizing effect on ventilation during sleep. In children, robust neuromuscular compensation mechanisms can augment minute ventilation without an EEG arousal or ventilatory overshoot. The cycling frequency and magnitude will also be dependent on lung volume and ventilation-perfusion matching as these parameters affect the time course of gas exchange abnormalities (83).

During wakefulness and sleep, the ventilatory response to hypercapnia is not significantly different between children with and without OSA $(66,67)$. Similarly, the mouth occlusion pressure $\left(\mathrm{P}_{0.1}\right)$, a measure of ventilatory drive independent of upper airway resistance, in response to hypercapnia was not significantly correlated with the obstructive AHI (84). Nevertheless, alterations in carbon dioxide levels of children with OSA have been reported during wakefulness and under anesthesia $(84,85)$. In awake, spontaneously breathing children, there was a positive correlation between resting end-tidal $\mathrm{CO}_{2}$ and OSA severity and a negative correlation between $\mathrm{P}_{0.1}$ responses to hypoxemia versus OSA severity (84). During halothane anesthesia in intubated children, the end-tidal $\mathrm{CO}_{2}$ was higher in children with OSA compared with control subjects (85). Finally, children with OSA had blunted ventilatory and respiratory timing responses to repeated brief, hypercapnia challenges compared with control children (86). Together, these studies suggest that abnormalities in ventilatory control, rather than simply increased upper airway resistance, may exist in patients with OSA. Whether the aforementioned alterations in ventilatory control in children with OSA are a primary phenomenon or secondary to adaptation to nocturnal gas exchange abnormalities has not been clearly established.

The role of ventilatory control instability in the pathophysiology of pediatric OSA remains to be determined. The highest density of obstructive events in children is observed in REM sleep, when ventilatory control is least important. However, variability of the EMGgg is highest in REM sleep, intermediate in stage 2 sleep, and lowest in slow wave sleep. The origin of this variability may be quite different. Stage 2 sleep is characterized by an active hypercapnic ventilatory response, negative pressure reflex, and an apneic threshold. In REM sleep, on the other hand, respiratory variability persists after deafferentation, suggesting that central, paroxysmal REM sleep processes underlie the variability.

\section{CONCLUSIONS}

The size of the pediatric airway is dependent on craniofacial and soft tissue structures. Increases in upper airway resistance, including any combination of narrowing/retropositioning of the maxilla/mandible or adenotonsillar hypertrophy, will predispose to OSA. In addition to anatomic factors, the stability of the upper airway is predicated on neuromuscular activation, arousal threshold, and ventilatory control. During wakefulness, there is robust activation of pharyngeal dilator muscles and a stable ventilatory pattern. At sleep onset, there is a marked reduction in the activation of airway muscles, an increased ventilatory variability particularly in REM sleep, and the appearance of an apneic threshold close to eupneic levels in non-REM sleep. Arousal from sleep contributes to ventilatory instability and therefore exacerbates obstructive cycling. During non-REM sleep, reduction in ventilatory drive during ventilatory overshoot results in sudden reductions in airway muscle activation, producing obstructive events (Figures 1-5). During REM sleep, paroxysmal reductions in pharyngeal dilator activity related to central REM sleep processes likely account for the predisposition toward obstructive events.

Conflict of Interest Statement: Neither author has a financial relationship with a commercial entity that has an interest in the subject of this manuscript.

\section{References}

1. Arens R, Marcus CL. Pathophysiology of upper airway obstruction: a developmental perspective. Sleep 2004;27:997-1019.

2. Katz ES, Marcus CL. Obstructive sleep apnea: children versus adults. In: Pack AI, editor. Sleep apnea: pathogenesis, diagnosis, and treatment, 2nd ed. New York: Informa Healthcare; 2007. (In press).

3. Montgomery-Downs HE, O'Brien LM, Gulliver TE, Gozal D. Polysomnographic characteristics in normal preschool and early schoolaged children. Pediatrics 2006;117:741-753.

4. Uliel S, Tauman R, Greenfeld M, Sivan Y. Normal polysomnographic respiratory values in children and adolescents. Chest 2004;125:872878.

5. Traeger N, Schultz B, Pollock AN, Mason T, Marcus CL, Arens R. Polysomnographic values in children 2-9 years old: additional data and review of the literature. Pediatr Pulmonol 2005;40:22-30.

6. Tabachnik E, Muller NL, Bryan AC, Levison H. Changes in ventilation and chest wall mechanics during sleep in normal adolescents. $J$ Appl Phys 1981;51:557-564.

7. Verhulst SL, Schrauwen N, Haentjens D, Van Gaal L, De Backer WA, Desager KN. Reference values for sleep-related respiratory variables in asymptomatic European children and adolescents. Pediatr Pulmonol 2007;42:159-167.

8. Ali NJ, Pitson DJ, Stradling JR. Snoring, sleep disturbance and behavior in 4-5 year olds. Arch Dis Child 1993;68:360-366.

9. Gislason T, Benediktsdottir B. Snoring, apneic episodes, and nocturnal hypoxemia among children 6 months to 6 years old. Chest 1995;107: 963-966.

10. Redline S, Tishler PV, Schluchter M, Aylor J, Clark K, Graham G. Risk factors for sleep-disordered breathing in children: associations with obesity, race, and respiratory problems. Am J Respir Crit Care Med 1999;159:1527-1532.

11. Lopes MC, Guilleminault C. Chronic snoring and sleep in children: a demonstration of sleep disruption. Pediatrics 2006;118:e741-e746.

12. Guilleminault C, Li KK, Khramstov A, Palombini L, Pelayo R. Breathing patterns in prepubertal children with sleep-related breathing disorders. Arch Pediatr Adolesc Med 2004;158:153-161.

13. Rosen C, D'Andrea L, Haddad G. Adult criteria for obstructive sleep apnea do not identify children with serious obstruction. Am Rev Respir Dis 1992;146:1231-1234.

14. Guilleminault C, Stoohs R, Clerk A, Cetel M, Maistros P. A cause of excessive daytime sleepiness: the upper airway resistance syndrome. Chest 1993;104:781-787.

15. Katz ES, Lutz JB, Black C, Marcus CL. Pulse transit time as a measure of arousal and respiratory effort in children with sleep-disordered breathing. Pediatr Res 2003;53:580-588.

16. Rizzi M, Onorato J, Andreoli A, Colombo S, Pecis M, Marchisio P, Morelli M, Principi N, Esposito S, Sergi M. Nasal resistances are useful in identifying children with severe obstructive sleep apnea before polysomnography. Int J Pediatr Otorhinolaryngol 2002;65:7-13.

17. Guilleminault $\mathrm{C}, \mathrm{Li} \mathrm{K}$, Quo S, Inouye RN. A prospective study on the surgical outcomes of children with sleep-disordered breathing. Sleep 2004;27:95-100.

18. Tauman R, O'Brien LM, Holbrook CR, Gozal D. Sleep pressure score: a new index of sleep disruption in snoring children. Sleep 2004;27:274278. 
19. Goh DY, Galster P, Marcus CL. Sleep architecture and respiratory disturbances in children with obstructive sleep apnea. Am J Respir Crit Care Med 2000;162:682-686.

20. Chervin RD, Burns JW, Subotic NS, Roussi C, Thelen B, Ruzicka DL. Correlates of respiratory cycle-related EEG changes in children with sleep-disordered breathing. Sleep 2004;27:116-121.

21. Kheirandish-Gozal L, Miano S, Bruni O, Ferri R, Pagani J, Villa MP, Gozal D. Reduced NREM sleep instability in children with sleep disordered breathing. Sleep 2007;30:450-457.

22. Dayyat E, Maarafeya MMA, Capdevila OS, Kheirandish-Gozal L, Montgomery-Downs HE, Gozal D. Nocturnal body position in sleeping children with and without obstructive sleep apnea. Pediatr Pulmonol 2007;42:374-379.

23. Litman RS, Wake N, Chan LML, McDonough JM, Sin S, Mahboubi S, Arens R. Effect of lateral positioning on upper airway size and morphology in sedated children. Anesthesiology 2005;103:484-488.

24. Arai YCP, Fukunaga K, Ueda W, Hamada M, Ikenaga H, Fukushima K. The endoscopically measured effects of airway maneuvers and the lateral position on airway patency in anesthetized children with adenotonsillar hypertrophy. Anesth Analg 2005;100:949-952.

25. Brouillette RT, Manoukian JJ, Ducharme FM, Oudjhane K, Earle LG, Ladan S, Morielli A. Efficacy of fluticasone nasal spray for pediatric obstructive sleep apnea. J Pediatr 2001;138:838-844.

26. Pirelli P, Saponara M, Guilleminault C. Rapid maxillary expansion in children with obstructive sleep apnea syndrome. Sleep 2004:27:761-766.

27. Guilleminault C, Huang Y, Glamann C, Li KK, Chan A. Adenotonsillectomy and obstructive sleep apnea in children: a prospective survey. Otolaryngol Head Neck Surg 2007;136:169-175.

28. Tauman R, Gulliver TE, Krishna J, Montgomery-Downs HE, O'Brien LM, Ivanenko A, Gozal D. Persistence of obstructive sleep apnea syndrome in children after adenotonsillectomy. J Pediatr 2006;149:803808.

29. Monahan KJ, Larkin EK, Rosen CL, Graham G, Redline S. Utility of noninvasive pharyngometry in epidemiologic studies of childhood sleepdisordered breathing. Am J Respir Crit Care Med 2002;165:1499-1503.

30. Arens R, McDonough JM, Costarino AT, Mahboubi S, Tayag-Kier CE, Maislin G, Schwab RJ, Pack AI. Magnetic resonance imaging of the upper airway structure of children with obstructive sleep apnea syndrome. Am J Respir Crit Care Med 2001;164:698-703.

31. Isono S, Shimada A, Utsugi M, Konno A, Nishino T. Comparison of static mechanical properties of the passive pharynx between normal children and children with sleep-disordered breathing. Am J Respir Crit Care Med 1998;157:1204-1212.

32. Kawashima S, Niikuni N, Chia-hung L, Takahasi Y, Kohno M, Nakajima I, Akasaka M, Sakata H, Akashi S. Cephalometric comparisons of craniofacial and upper airway structures in young children with obstructive sleep apnea syndrome. Ear Nose Throat J 2000;79:499-506.

33. Fregosi RF, Quan SF, Kaemingk KL, Morgan WJ, Goodwin JL, Cabrera R, Gmitro A. Sleep-disordered breathing, pharyngeal size and soft tissue anatomy in children. $J$ Appl Phys 2003;95:2030-2038.

34. Donnelly LF, Surdulescu V, Chini BA, Casper KA, Poe SA, Amin RS. Upper airway motion depicted at cine MR imaging performed during sleep: comparison between young patients with and those without obstructive sleep apnea. Radiology 2003;227:239-245.

35. Lofstrand-Tidestrom B, Thilander B, Ahlqvist-Rastad J, Jakobsson OP, Hultcrantz E. Breathing obstruction in relation to craniofacial and dental arch morphology in 4-year-old children. Eur J Orthod 1999;21: 323-332.

36. Behlfelt K, Linder-Aronson S, McWilliam J, Neander P, Laage-Hellman J. Cranio-facial morphology in children with and without enlarged tonsils. Eur J Orthod 1990;12:233-243.

37. Zettergren-Wijk L, Forsberg CM, Linder-Aronson S. Changes in dentofacial morphology after adeno-tonsillectomy in young children with obstructive sleep apnoea: a 5-year follow-up study. Eur J Orthod 2006;28:319-326.

38. Ozdemir H, Altin R, Sogut A, Cinar F, Mahmutyazicioglu K, Kart L, Uzun L, Davsanci H, Gundogdu S, Tomac N. Craniofacial differences according to AHI scores of children with obstructive sleep apnoea syndrome: cephalometric study in 39 patients. Pediatr Radiol 2004;34: 393-399.

39. Ronen O, Malhotra A, Pillar G. The influence of gender and age on upper airway length during development. Sleep 2007;30:A68.

40. Malhotra A, Huang Y, Fogel RB, Pillar G, Edwards JK, Kikinis R, Loring SH, White DP. The male predisposition to pharyngeal collapse: importance of airway length. Am J Respir Crit Care Med 2002; $166: 1388-1395$.
41. Jeans WD, Fernando DCJ, Maw AR, Leighton BC. A longitudinal study of the growth of the nasopharynx and its contents in normal children. Br J Radiol 1981;54:117-121.

42. Arens R, Sin S, McDonough JM, Palmer JM, Dominguez T, Meyer H, Wootton DM, Pack AI. Changes in upper airway size during tidal breathing in children with obstructive sleep apnea syndrome. Am J Respir Crit Care Med 2005;171:1298-1304.

43. Donnelly LF, Casper KA, Chen B. Correlation on cine MR imaging of size of adenoid and palatine tonsils with degree of upper airway motion in asymptomatic sedated children. AJR Am J Roentgenol 2002;179:503-508.

44. Arens R, McDonough JM, Corbin AM, Rubin NK, Carroll ME, Pack AI, Liu J, Udupa JK. Upper airway size analysis by magnetic resonance imaging of children with obstructive sleep apnea syndrome. Am J Respir Crit Care Med 2003;167:65-70.

45. Agren K, Nordlander B, Linder-Aronsson S, Zettergren-Wijk L, Svanborg E. Children with nocturnal upper airway obstruction: postoperative orthodontic and respiratory improvement. Acta Otolaryngol 1998;118: $581-587$.

46. Hultcrantz E, Larson M, Hellquist R, Ahlquist-Rastad J, Svanholm H, Jakobsson OP. The influence of tonsillar obstruction and tonsillectomy on facial growth and dental arch morphology. Int J Pediatr Otorhinolaryngol 1991;22:125-134.

47. Arens R, McDonough JM, Corbin AM, Hernadez ME, Maislin G, Schwab RJ, Pack AI. Linear dimensions of the upper airway structure during development: assessment by magnetic resonance imaging. Am J Respir Crit Care Med 2002;165:117-122.

48. Tasker C, Crosby JH, Stradling JR. Evidence of persistence of upper airway narrowing during sleep, 12 years after adenotonsillectomy. Arch Dis Child 2002;86:34-37.

49. Morton S, Rosen C, Larkin E, Tishler P, Aylor J, Redline S. Predictors of sleep-disordered breathing in children with a history of tonsillectomy and/or adenoidectomy. Sleep 2001;24:823-829.

50. Marcus CL, Curtis S, Koerner CB, Joffe A, Serwint JR, Loughlin GM. Evaluation of pulmonary function and polysomnography in obese children and adolescents. Pediatr Pulmonol 1996;21:176-183.

51. Silvestri JM, Weese-Meyer DE, Bass MT, Kenny AS, Hauptman SA, Pearsall SM. Polysomnography in obese children with a history of sleep-associated breathing disorders. Pediatr Pulmonol 1993;16:124 129.

52. Mitchell RB, Kelly J. Outcome of adenotonsillectomy for obstructive sleep apnea in obese and normal-weight children. Otolaryngol Head Neck Surg 2007;137:43-48.

53. Verhulst SL, Schrauwen N, Haentjens D, Suys B, Rooman RP, Gaal LV, De Backer WA, Desager KN. Sleep-disordered breathing in overweight and obese children and adolescents: prevalence, characteristics and the role of fat distribution. Arch Dis Child 2007;92:205-208.

54. De Vuono IM, Zanoteli E, de Oliveira AS, Fujita RR, Pignatari SSN, Pizarro GU, Pradelle-Hallinan ML, Moreira GA. Histological analysis of palatopharyngeal muscle from children with snoring and obstructive sleep apnea syndrome. Int J Pediatr Otorhinolaryngol 2007;71:283-290.

55. Huang J, Marcus C, Melendres C, Karamessinis L, Pepe M, Samuel J, Abi-Raad R, Trescher W, Colrain I. Respiratory sensation during sleep in children with obstructive sleep apnea syndrome [abstract]. Sleep 2007;30(Suppl):A67.

56. Goldbart AD, Goldman JL, Li RC, Brittian KR, Tauman R, Gozal D. Differential expression of cysteinyl leukotriene receptors 1 and 2 in tonsils of children with obstructive sleep apnea syndrome or recurrent infection. Chest 2004;126:13-18.

57. Goldbart AD, Goldman JL, Veling MC, Gozal D. Leukotriene modifier therapy for mild sleep-disordered breathing in children. Am J Respir Crit Care Med 2005;172:364-370.

58. Kheirandish L, Goldbart AD, Gozal D. Intranasal steroids and oral leukotriene modifier therapy in residual sleep-disordered breathing after tonsillectomy and adenoidectomy in children. Pediatrics 2006; 117:e61-e66.

59. Wilson SL, Thatch BT, Brouillette RT, Abu-Osba YK. Upper airway patency in the human infant: influence of airway pressure and posture. J Appl Phys 1980;48:500-504.

60. Marcus CL, McColley SA, Carroll JL, Loughlin GM, Smith PL, Schwartz AR. Upper airway collapsibility in children with obstructive sleep apnea syndrome. J Appl Phys 1994;77:918-924.

61. Katz ES, Marcus CL, White DP. Influence of airway pressure on genioglossus activity during sleep in normal children. Am J Respir Crit Care Med 2006;173:902-909. 
62. Marcus CL, Katz ES, Lutz J, Black CA, Galster P, Carson KA. Upper airway dynamic responses in children with the obstructive sleep apnea syndrome. Pediatr Res 2005;57:99-107.

63. Fregosi RF, Quan SF, Morgan WL, Goodwin JL, Cabrera R, Shareif I, Fridel KW, Bootzin RR. Pharyngeal critical closing pressure in children with mild sleep-disordered breathing. J Appl Physiol 2006; 101:734-739.

64. Bandla P, Pepe M, Samuel J, Karamessinis L, Brooks LJ, Mason TA, Marcus CL. The effect of puberty on upper airway collapsibility [abstract]. Am J Respir Crit Care Med 2006;173:A734.

65. Marcus CL, Fernandes Do Prado LB, Lutz J, Katz ES, Black CA, Galster P, Carson KA. Developmental changes in upper airway dynamics. J Appl Phys 2004;97:98-108.

66. Marcus CL, Lutz J, Carroll JL, Bamford O. Arousal and ventilatory responses during sleep in children with obstructive sleep apnea. J Appl Phys 1998;84:1926-1936.

67. Marcus CL, Gozal D, Arens R, Basinski DJ, Omlin KJ, Keens TG, Ward SL. Ventilatory responses during wakefulness in children with obstructive sleep apnea. Am J Respir Crit Care Med 1994;149:715-721.

68. Katz ES, White DP. Genioglossus activity in children with obstructive sleep apnea during wakefulness and sleep onset. Am J Respir Crit Care Med 2003;168:664-670.

69. Gozal D, Burnside MM. Increased upper airway collapsibility in children with obstructive sleep apnea during wakefulness. Am J Respir Crit Care Med 2004;169:163-167.

70. Katz ES, White DP. Genioglossus activity during sleep in normal control subjects and children with obstructive sleep apnea. Am J Respir Crit Care Med 2004;170:553-560.

71. Henderson-Smart DJ, Read DJC. Reduced lung volume during behavioral active sleep in the newborn. J Appl Phys 1979;46:1081-1085.

72. Van de Graaff WB. Thoracic influence on upper airway patency. J Appl Phys 1988;65:2124-2131.

73. Stanchina ML, Malhotra A, Fogel RB, Trinder J, Edwards JK, Schory K, White DP. The influence of lung volume on pharyngeal mechanics, collapsibility, and genioglossus muscle activation during sleep. Sleep 2003;26:851-856.

74. Marcus CL, Moreira GA, Bamford O, Lutz J. Response to inspiratory resistive loading during sleep in normal children and children with obstructive apnea. J Appl Phys 1999;87:1448-1454.
75. Younes M. Role of arousals in the pathogenesis of obstructive sleep apnea. Am J Respir Crit Care Med 2004;169:623-633.

76. O'Brien LM, Mervis CB, Holbrook CR, Bruner JL, Klaus CJ, Rutherford J, Raffield TJ, Gozal D. Neurobehavioral implications of habitual snoring in children. Pediatrics 2004;114:44-49.

77. Moreira GA, Tufik S, Nery LE, Lutz J, Verfaille K, Luan X, Marcus CL. Acoustic arousal responses in children with obstructive sleep apnea. Pediatr Pulmonol 2005;40:300-305.

78. McNamara F, Issa F, Sullivan C. Arousal pattern following central and obstructive breathing abnormalities in infants and children. $J$ Appl Physiol 1996;81:2651-2657.

79. Khan A, Quarashi M, Kwiatkowski K, Cates D, Rigatto H. Measurement of the $\mathrm{CO}_{2}$ apneic threshold in newborn infants: possible relevance for periodic breathing and apnea. J Appl Phys 2005;98: 1171-1176.

80. Waggener TB, Frantz ID, Cohlan BA, Stark AR. Mixed and obstructive apneas are related to ventilatory oscillations in premature infants. J Appl Phys 1989;66:2818-2826.

81. Al-Saif S, Alvaro R, Manfreda J, Kwiatkowski K, Cates D, Rigatto H. Inhalation of low $(0.5 \%-1.5 \%) \mathrm{CO}_{2}$ as a potential treatment for apnea of prematurity. Semin Perinatol 2001;25:100-106.

82. Wellman A, Jordan AS, Malhotra A, Fogel RB, Katz ES, Schory K, Edwards JK, White DP. Ventilatory control and airway anatomy in obstructive sleep apnea. Am J Respir Crit Care Med 2004;170:12251232.

83. Poets CF, Rau GA, Neuber K, Gappa M, Seidenberg J. Determinants of lung volume in spontaneously breathing preterm infants. Am J Respir Crit Care Med 1997;155:649-653.

84. Fregosi RF, Quan SF, Jackson AC, Kaemingk KL, Morgan WJ, Goodwin JL, Reeder JC, Cabrera RK, Antonio E. Ventilatory drive and the apnea-hypopnea index in six-to-twelve year old children. BMC Pulm Med 2004;4:4

85. Waters KA, McBrien F, Stewart P, Hinder M, Wharton S. Effects of OSA, inhalational anesthesia, and fentanyl on the airway and ventilation of children. J Appl Phys 2002;92:1987-1994.

86. Gozal D, Arens R, Omlin KJ, Ben-Ari G, Aljadeff G, Harper RM, Keens TG. Ventilatory response to consecutive short hypercapnic challenges in children with obstructive sleep apnea. J Appl Physiol 1995;79:1608-1614. 